\title{
Synthesis, Characterization and Theoretical Insights into Molecular Properties of 2-(4-fluorophenyl)-4H-chromen-4-one
}

\author{
Rohit S. Shinde*
}

PG Department of Chemistry, Mahatma Gandhi Vidyamandir's Arts, Science and Commerce College (Affiliated to S.P.P.U., Pune), Manmad, Nashik - 423 104, Maharashtra, India.

\section{A R T IC LE DET A I L S}

Article history:

Received 23 March 2021

Accepted 08 April 2021

Available online 20 April 2021

\section{Keywords:}

DFT

B3LYP/6-31G(d,p)

Flavone

\begin{abstract}
A B S T R A C T
Flavone scaffold is one of the most often perceived parts in biologically active organic compounds. In light of this, a flavone; 2-(4-fluorophenyl)-4H-chromen-4-one (FPC) has been synthesized, characterized and studied by using density functional theory (DFT) at B3LYP/6-31G(d,p) basis set. The geometry of the FPC molecules has been optimized by using B3LYP/6-31G(d,p) basis set and in-depth structural analysis on bond lengths and bond angles has been discussed. The HOMO-LUMO analysis and various quantum chemical parameters are computed and discussed for the better understanding of chemical behaviour of the title molecule. Molecular electrostatic potential (MEP) surface investigation is presented to understand the reactivity sites of the title molecule.
\end{abstract}

\section{Introduction}

Flavonoids are a diverse group of plant-derived compounds [1]. They are well-known plant secondary metabolites that have been discovered in foods such as bananas, vegetables, olive oil, tea, and red wine. The pharmacological potential of natural products is gaining popularity [2-4]. Researchers have been studying flavonoids as oxidative reaction inhibitors and anti-inflammatory agents in recent years $[5,6]$. They have been shown to have anxiolytic, antiviral, antiprotozoal, anti-microbial, and anti-carcinogenic properties [7-12]. Usually chalcones are the precursors used for the synthesis of flavones. Chalcones also possess notable pharmacological properties [13-21]. Green chemistry principles have been utilized for the synthesis of variety of compounds [22-26]. The ultrasound strategy has been previously used for the synthesis of chalcones [27]. Accordingly ultrasound methodology has been employed for the synthesis of precursor, i.e. chalcone. DFT computations provide investigators with a plethora of data about the molecules' spectral and quantum chemical parameters, enabling researchers to examine chemical behaviour [28-37]. The chromones 6,8-dichloro-2-(4-chlorophenyl)-4Hchromen-4-one and 6,8-dichloro-2-(4-Methoxyphenyl)- 4H-chromen-4One were previously studied using DFT methodology to explore structural and spectroscopic properties [38, 39]. DFT approaches have already been shown to be useful in studies of reaction mechanisms. Assigning the correct UV-Visible and vibrational bands has been an easy task due to the contrast of theoretical and experimental IR vibrations. In view of the above, this present work made on a DFT study of 2-(4-fluorophenyl)-4Hstructural, chromen-4-one's spectral, and molecular properties.

\section{Experimental Methods}

The chalcone (3) was synthesized from 2-hycroxyacetopheone (1) and 4-fluorobenzaldehyde (2) as per previously reported method [21]. The chalcone (3) (0.01 mol) was taken in round bottom flask containing DMSO solvent. To this catalytic amount of $I_{2}$ was mixed and resulting mixture was refluxed until formation of the product. The reaction was monitored by TLC. After completion of the reaction, reaction mixture was transferred in a beaker containing crushed ice. The precipitated product formed was filtered, washed with water and sodium thiosulfate until free from $I_{2}$. The

crude product was recrystallized to afford pure product (4). The synthesis is given in Scheme 1.

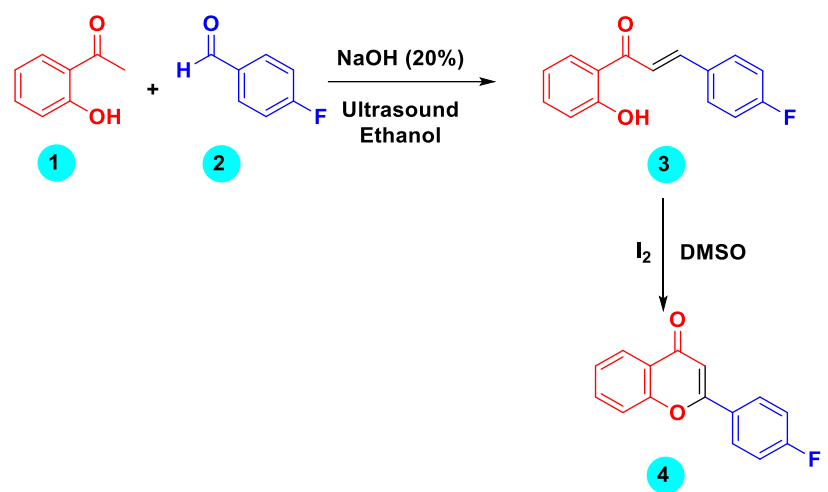

Scheme 1 Synthesis of 2-(4-fluorophenyl)-4H-chromen-4-one

Table 1 Physicochemical and spectral data of FPC

\begin{tabular}{ll}
\hline Properties & Characteristics \\
\hline Systematic Name of the Product & 2-(4-fluorophenyl)-4H-chromen-4-one \\
Abbreviation used & FPC \\
Physicochemical data & Yield: $75 \%$, Colour: White solid, m.p. : $155^{\circ} \mathrm{C}$ \\
${ }^{1} \mathrm{H} \mathrm{NMR}$ & $400 \mathrm{MHz}, \mathrm{d}(\mathrm{ppm}): 6.73-6.75(\mathrm{~s}, 1 \mathrm{H}), 7.41(\mathrm{~m}$, \\
$\left(400 \mathrm{MHz}, \mathrm{CDCl}_{3}\right)$ & $1 \mathrm{H}), 7.69(\mathrm{~m}, 1 \mathrm{H}), 7.51-7.53(\mathrm{~m}, 1 \mathrm{H}), 8.19(\mathrm{~m}$, \\
& $1 \mathrm{H}), 7.45-7.47(\mathrm{~m}, 2 \mathrm{H}), 7.81-7.83(\mathrm{~m}, 2 \mathrm{H})$ \\
HRMS & Calculated: $240.0586[\mathrm{M}+\mathrm{H}]$, \\
& Observed: $240.0588[\mathrm{M}+\mathrm{H}]$. \\
\hline
\end{tabular}

\subsection{Computational Details}

DFT calculations were performed on an Intel (R) Core (TM) i5 computer using Gaussian-03 program package without any constraint on the geometry [40]. The geometry of the molecules studied here is optimized by DFT/B3LYP method using 6-31G (d, p) basis set. The FMO analysis and quantum chemical study has been performed using same basis set. Absorption energies ( $\lambda$ in $\mathrm{nm}$ ), oscillator strength ( $\mathrm{f}$ ), and transitions of title molecule have been calculated at TD-B3LYP/6-31G $(d, p)$ level of theory for B3LYP/6-31G(d,p) optimized geometries. To investigate the reactive sites of the title molecules, MEP was computed using the same method. All the calculations were carried out for the optimized structure in the gas phase. 


\section{Results and Discussion}

\subsection{Optimized Molecular Structure}

The optimized molecular structure of the title molecule FPC is given in Fig. 1. The molecule FPC is having C1 point group symmetry and the dipole moment is 5.0279 Debye. The optimized geometrical parameters; bond lengths and bond angles of the title molecule have been computed and presented here in Table 2 and Table 3 . In the molecule FPC, the $\mathrm{C}=0$ (C16020) bond length is $1.2307 \AA$. The C-F (C20-F26) bond length is $1.3462 \AA$. The bond lengths in C-0 are $1.3649 \AA$ (C7-023) and $1.3734 \AA$ (C13-023). Amongst aromatic $\mathrm{C}=\mathrm{C}$ bond lengths, $\mathrm{C} 3-\mathrm{C} 4$ bond is the longest (1.406 $\AA$ ) and the shortest is C14-C16 (1.3868 $\AA$ ). Other bond lengths are also in good agreement. All the bond angles are also in good agreement.

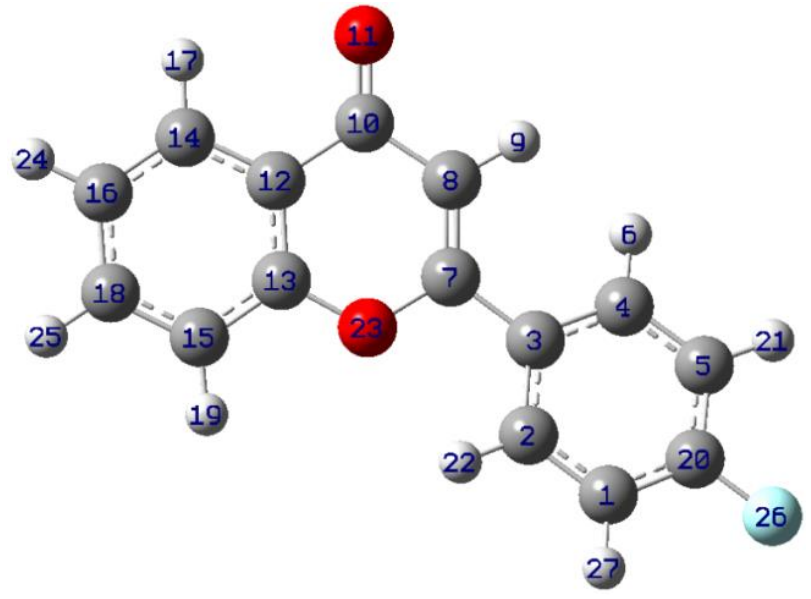

Fig. 1 Optimized molecular structure of FPC

Table 2 Optimized bond lengths of FPC at B3LYP/6-31G(d.p)

\begin{tabular}{llll}
\hline \multicolumn{3}{c}{ Bond Lengths $(\AA)$} \\
C1-C2 $1-C 20$ & 1.3917 & C10-O11 & 1.2307 \\
C1-H27 & 1.39 & C10-C12 & 1.4817 \\
C2-C3 & 1.0843 & C12-C13 & 1.4 \\
C2-H22 & 1.4058 & C12-C14 & 1.4036 \\
C3-C4 & 1.0832 & C13-C15 & 1.398 \\
C3- C7 & 1.406 & C13-O23 & 1.3734 \\
C4- C5 & 1.4742 & C14-C16 & 1.3868 \\
C4-H6 & 1.3903 & C14-H17 & 1.085 \\
C5- C20 & 1.0843 & C15-C18 & 1.3889 \\
C5- H21 & 1.3913 & C15-H19 & 1.0846 \\
C7- 08 & 1.0842 & C16-C18 & 1.4046 \\
C7-023 & 1.3583 & C16-H24 & 1.0854 \\
C8-H9 & 1.3649 & C18-H25 & 1.0858 \\
C8-C10 & 1.0823 & C20-F26 & 1.3462 \\
\hline
\end{tabular}

Table 3 Optimized bond angles of FPC at B3LYP/6-31G(d.p)

\begin{tabular}{llll}
\hline & \multicolumn{3}{c}{ Bond Angles ${ }^{\circ}$ ) } \\
\hline C2-C1-C20 & 118.7831 & C10-C12-C13 & 119.844 \\
C2-C1-H27 & 121.5646 & C10-C12-C14 & 121.5517 \\
C20-C1-H27 & 119.6521 & C13-C12-C14 & 118.6032 \\
C1-C2-C3 & 120.9161 & C12-C13-C15 & 121.5911 \\
C1-C2-H22 & 119.6387 & C12-C13-O23 & 121.8179 \\
C3-C2-H22 & 119.444 & C15-C13-O23 & 116.5899 \\
C2-C3-C4 & 118.6536 & C12-C14-O16 & 120.507 \\
C2-C3-C7 & 120.4998 & C12-C14-H17 & 117.3648 \\
C4-C3-C7 & 120.8465 & C16-C14-H17 & 122.1282 \\
C3-C4-C5 & 120.9707 & C13-C15-C18 & 118.7177 \\
C3-C4-H6 & 120.0384 & C13-C15-H19 & 119.3815 \\
C5-C4-H6 & 118.9789 & C18-C15-H19 & 121.9007 \\
C4-C5-C20 & 118.756 & C14-C16-C18 & 119.8684 \\
C4-C5-H21 & 121.5636 & C14-C16-H24 & 120.2573 \\
C20-C5-H21 & 119.6766 & C18-C16-H24 & 119.8743 \\
C3-C7-C8 & 126.1016 & C15-C18-C16 & 120.7124 \\
C3-C7-O23 & 111.9959 & C15-C18-H25 & 119.3558 \\
C8-C7-O23 & 121.8985 & C16-C18-H25 & 119.9317 \\
C7-C8-H9 & 120.2747 & C1-C20-C5 & 121.9145 \\
C7-C8-C10 & 122.509 & C1-C20-F26 & 119.1022 \\
H9-C8-C10 & 117.2078 & C5-C20-F26 & 118.9823 \\
C8-C10-011 & 123.403 & C7-O23-C13 & 120.055 \\
C8-C10-C12 & 113.8609 & 011-C10-C12 & 122.7342 \\
\hline
\end{tabular}

\subsection{Global Descriptors Study}

The pictorial representation of HOMO-LUMO orbitals is given in Fig. 2. The electronic parameters such as $\mathrm{E}_{\text {номо, }} \mathrm{E}_{\text {цuмо, }}$ ionization enthalpy (I), and electron affinity (A) are given in Table 4. The quantum chemical parameters like electronegativity $(\chi)$, absolute hardness $(\eta)$, softness $(\sigma)$, electrophilicity $(\omega)$, chemical potential (Pi) are presented in Table 5. The frontier molecular orbital (FMO) analysis suggests that the energy gap in the molecule FPC is $4.55 \mathrm{eV}$. The lower HOMO-LUMO energy gap demonstrates the inevitable charge transfer is happening within the molecule. The global softness ( $\sigma$ ), and the absolute hardness $(\eta)$ values are 0.4396 and $2.275 \mathrm{eV}$ respectively. The ease of removal of an electron is governed by its chemical potential $\mathrm{Pi}$ and it is likewise identified with its electronegativity $(\chi)$. A good electrophile is described by a higher value of global electrophilicity $(\omega)$ and the higher value of $\omega$ indicates good nucleophile. Observed results suggest that the molecule FPC has a higher value of global electrophilicity ( $\omega=3.7394 \mathrm{eV}$ ), and so it is most likely to accept electrons readily and also would undergo nucleophilic attack easily. As Pi value increases, the ability of a molecule to lose an electron increases. The maximum charge transfer is in the title molecule is $1.8132 \mathrm{eV}$.

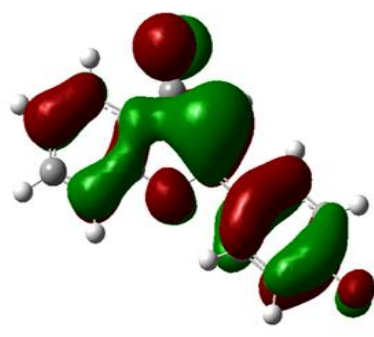

номо

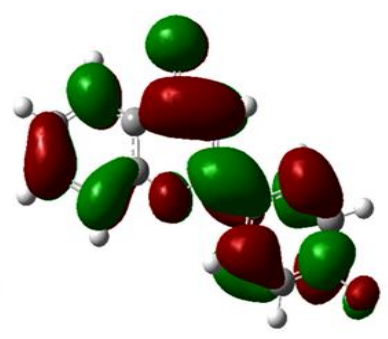

LUMO
Fig. 2 HOMO-LUMO properties of FPC

Table 4 Electronic parameters of FPC

\begin{tabular}{llllll}
\hline $\begin{array}{l}\text { ETotal } \\
\text { (a.u. })\end{array}$ & $\begin{array}{l}\text { Eномо }_{(\mathrm{eV})} \\
-827.31\end{array}$ & $\begin{array}{l}\text { ELUmo } \\
(\mathrm{eV})\end{array}$ & $\begin{array}{l}\mathrm{I} \\
(\mathrm{eV})\end{array}$ & $\begin{array}{l}\mathrm{A} \\
(\mathrm{eV})\end{array}$ & $\begin{array}{l}\mathrm{E}_{\mathrm{g}} \\
(\mathrm{eV})\end{array}$ \\
\hline
\end{tabular}

Note: Abbreviations: I, ionization potential; $A$, electron affinity; Note: $I=-E_{\text {номо }}$ and $A=-E_{\text {LUMO }}$

$\underline{\text { Table } 5 \text { Global reactivity parameters of FPC }}$

\begin{tabular}{lllllll}
\hline $\begin{array}{l}\eta \\
(\mathrm{eV})\end{array}$ & $\begin{array}{l}\eta \\
(\mathrm{eV})\end{array}$ & $\begin{array}{l}\sigma \\
\left(\mathrm{eV}^{-1}\right)\end{array}$ & $\begin{array}{l}\omega \\
(\mathrm{eV})\end{array}$ & $\begin{array}{l}\mathrm{Pi} \\
(\mathrm{eV})\end{array}$ & $\begin{array}{l}\Delta \text { Nmax } \\
(\mathrm{eV})\end{array}$ & $\begin{array}{l}\text { Dipole } \\
\text { moment } \\
(\text { Debye })\end{array}$ \\
\hline 4.125 & 2.275 & 0.4396 & 3.7394 & -4.125 & 1.8132 & 3.4640 \\
\hline
\end{tabular}

Note: $\chi=(I+A) / 2 ; \eta=(I-A) / 2 ; \sigma=1 / \eta ; \omega=P i^{2} / 2 \eta ; P i=-\chi ; \Delta N \max =-P i / \eta$. Abbreviations: $\chi$, electronegativity; $\eta$ absolute hardness; $\sigma$, global softness; $\omega$, global electrophilicity; $P i$, chemical potential; $\Delta N$ max, maximum no. of electron transferred.

\subsection{Mulliken Atomic Charges}

The Mulliken atomic charges of the FPC molecule are calculated by DFT/B3LYP method with 6-31G(d,p) basis set in the gaseous phase and are given in Table 6. Mulliken atomic charges reveal that all the hydrogen atoms have a net positive charge but $\mathrm{H} 17$ and $\mathrm{H} 22$ atoms have a more positive charge than other hydrogen atoms and therefore they are more acidic. These two hydrogen atoms are flanked between two $\mathrm{C}=\mathrm{C}$ groups. Amongst, carbon atoms, the $\mathrm{C} 10$ atom have the highest net positive charge $(0.410979)$ as it is attached to an electronegative oxygen atom. On the other hand C8 atom has the highest negative charge (-0.186337).

\begin{tabular}{llll}
\multicolumn{2}{l}{ Table 6 Mulliken atomic charges } \\
\hline Atom & Charge & Atom & Charge \\
\hline 1 C & -0.143342 & $14 \mathrm{C}$ & -0.112416 \\
2 C & -0.098615 & $15 \mathrm{C}$ & -0.119032 \\
3 C & 0.045639 & $16 \mathrm{C}$ & -0.088379 \\
$4 \mathrm{C}$ & -0.105502 & $17 \mathrm{H}$ & 0.124073 \\
$5 \mathrm{C}$ & -0.148913 & $18 \mathrm{C}$ & -0.085850 \\
$6 \mathrm{H}$ & 0.109620 & $19 \mathrm{H}$ & 0.104105 \\
$7 \mathrm{C}$ & 0.315796 & $20 \mathrm{C}$ & 0.364054 \\
$8 \mathrm{C}$ & -0.186337 & $21 \mathrm{H}$ & 0.113232 \\
$9 \mathrm{H}$ & 0.109041 & $22 \mathrm{H}$ & 0.115507 \\
$10 \mathrm{C}$ & 0.410979 & $23 \mathrm{O}$ & -0.544596 \\
$11 \mathrm{O}$ & -0.519430 & $24 \mathrm{H}$ & 0.096524 \\
$12 \mathrm{C}$ & 0.036938 & $25 \mathrm{H}$ & 0.098476 \\
$13 \mathrm{C}$ & 0.285938 & $26 \mathrm{~F}$ & -0.288878 \\
- & - & $27 \mathrm{H}$ & 0.111367 \\
\hline
\end{tabular}




\subsection{Molecular Electrostatic Potential Surface Analysis}

Fig. 3 shows the MEP plot of FPC. The use of MEP plot can be used to evaluate phenomena such as nucleophilic and electrophilic positions, solvent effects, hydrogen bonding interactions, and so on. MEP is mainly used to establish the reactive sites of molecules, enabling researchers to predict how one particle will interact with another. The various electrostatic potential values at the molecule's surface are expressed by different colours. Electrophilic reactivity is correlated with the red and yellow zones, which lead to high electron density. The blue sections, on the other hand, reflect low electron density and nucleophilic reactivity, while the green colours represent regions of zero potential. The studied molecule FPC should high electrophilic reactivity zone from MEP plot.

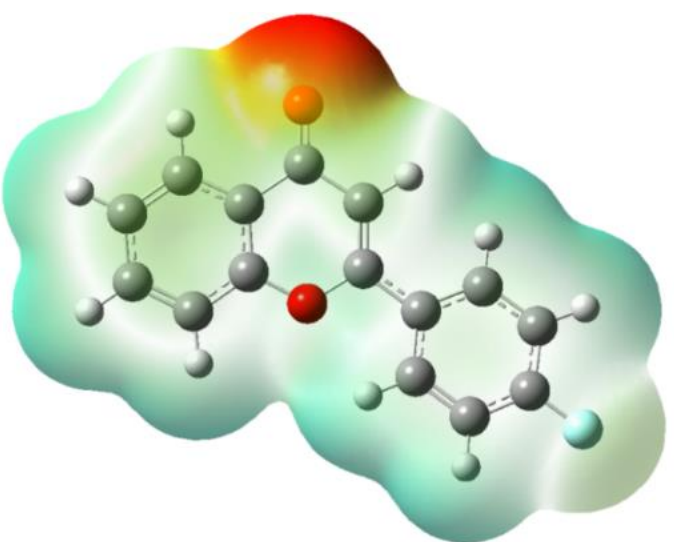

Fig. 3 Molecular electrostatic potential plot of FPC

\section{Conclusion}

The DFT approach was used to analyse different aspects of FPC using the B3LYP/6-31G (d,p) basis set. The tile molecule 2-(4-fluorophenyl)-4Hchromen-4-one geometry is optimised using the B3LYP/6-31G(d,p) basis sequence. It has been addressed how to configure geometrical parameters such as bond lengths and bond angles. Frontier molecular orbital analysis shows that the molecule is undergoing the irrevocable charge transition. Electronegativity, absolute hardness, global softness, global electrophilicity, chemical potential, maximum charge transmitted, and other quantum chemical parameters are measured and addressed. The electrophilic reactivity sites in the title molecule has been observed from the molecular electrostatic potential surface plot. Results of Mulliken atomic charges reveal that $\mathrm{H} 17$ and $\mathrm{H} 22$ atoms have a more positive charge and hence more acidic.

\section{Acknowledgments}

Author is grateful to Prof. (Dr.) A.B. Sawant and Prof. (Dr.) T.B. Pawar for generous help in the Gaussian study. Author acknowledges Department of Chemistry, Arts, Science and Commerce College, Manmad, MS, India for providing the research facility.

\section{References}

[1] B. Havsteen, Flavonoids, a class of natural products of high pharmacological potency, Biochem. Pharmacol. 32(7) (1983) 1141-1148.

[2] X. Zu Zhu, X.Y. Li, J. Liu, Recent pharmacological studies on natural products in China, Eur. J. Pharmacol. 500(1-3) (2004) 221-230.

[3] Saeed, Aamer, Isocoumarins, miraculous natural products blessed with diverse pharmacological activities, Eur. J. Med. Chem. 116 (2016) 290-317.

[4] Pietta, Pier-Giorgio, Flavonoids as antioxidants, J. Nat. Prod. 63(7) (2000) 1035-1042.

[5] G. Agati, E. Azzarello, S. Pollastri, M. Tattini, Flavonoids as antioxidants in plants: location and functional significance, Plant Sci. 196 (2012) 67-76.

[6] M. Serafini, I. Peluso, A. Raguzzini, Flavonoids as anti-inflammatory agents, Proc. Nutr. Soc. 69(3) (2010) 273-278.

[7] A.C. Paladini, M. Marder, H. Viola, C. Wolfman, C. Wasowski, J.H. Medina, Flavonoids and the central nervous system: from forgotten factors to potent anxiolytic compounds, J. Pharm. Pharmacol. 51(5) (1999) 519-526.

[8] S. Lalani, C.L. Poh, Flavonoids as antiviral agents for Enterovirus A71 (EVA71), Viruses 12(2) (2020) 184.

[9] A.M. Nour, S.A. Khalid, M. Kaiser, R. Brun, E.A. Wail, T.J. Schmidt, The antiprotozoal activity of methylated flavonoids from Ageratum conyzoides L., J. Ethnopharmacol. 129(1) (2010) 127-130.

[10] D.D. Orhan, B. Özçelik, S. Özgen, and F.Ergun, Antibacterial, antifungal, and antiviral activities of some flavonoids, Microbiol. Res. 165(6) (2010) 496-504.
[11] G. Seelinger, I. Merfort, U. Wölfle, C.M. Schempp, Anti-carcinogenic effects of the flavonoid luteolin, Molecules 13(10) (2008) 2628-2651.

[12] V.A. Adole, T.B. Pawar, B.S. Jagdale, Aqua-mediated rapid and benign synthesis of 1,2,6,7-tetrahydro- $8 H$-indeno[5,4- $b$ ] furan-8-one-appended novel 2arylidene indanones of pharmacological interest at ambient temperature, J. Chin. Chem. Soc. 67(2) (2020) 306-315.

[13] C. Díaz-Tielas, E. Graña, M.J. Reigosa, A.M. Sánchez-Moreiras, Biological activities and novel applications of chalcones, Planta Daninha. 34(3) (2016) 607-616.

[14] A. Rani, A. Anand, K. Kumar, V. Kumar, Recent developments in biological aspects of chalcones: the odyssey continues, Expert Opin. Drug Discov. 14(3) (2019) 249-288.

[15] V.A. Adole, R.H. Waghchaure, S.S. Pathade, M.R. Patil, T.B. Pawar, B.S. Jagdale, Solvent-free grindstone synthesis of four new (E)-7-(arylidene)-indanones and their structural, spectroscopic and quantum chemical study: a comprehensive theoretical and experimental exploration, Mol. Simul. 46 (2020) 1045-1054.

[16] R.A. Shinde, V.A. Adole, B.S. Jagdale, T.B. Pawar, B.S. Desale, R.S. Shinde, Efficient synthesis, spectroscopic and quantum chemical study of 2, 3dihydrobenzofuran labelled two novel arylidene indanones: A comparative theoretical exploration, Mat. Sci. Res. India. 17(2) (2020) 146-161.

[17] R.A. Shinde, V.A. Adole, B.S. Jagdale, T.B. Pawar, Experimental and theoretical studies on the molecular structure, FT-IR, NMR, HOMO, LUMO, MESP, and reactivity descriptors of $(E)$-1-(2,3-Dihydrobenzo[b][1,4]dioxin-6-yl)-3-(3,4,5trimethoxyphenyl) prop-2-en-1-one, Mat. Sci. Res. India 17 (2020) 54-72.

[18] B. Ardiansah, Chalcones bearing N, O, and S-heterocycles: Recent notes on their biological significances, J. Appl. Pharm. Sci. 9 (2019) 117-129.

[19] V.A. Adole, P.B. Koli, R.A. Shinde, R.S. Shinde, Computational insights on molecular structure, electronic properties, and chemical reactivity of $(E)$-3-(4chlorophenyl)-1-(2-hydroxyphenyl)prop-2-en-1-one, Mat. Sci. Res. India 17 (2020) 41-53.

[20] B.P. Bandgar, S.A. Patil, R.N. Gacche, B.L. Korbad, B.S. Hote, S.N. Kinkar, S.S. Jalde, Synthesis and biological evaluation of nitrogen-containing chalcones as possible anti-inflammatory and antioxidant agents, Bioorg. Med. Chem. Lett. 20(2) (2010) 730-733.

[21] V.A. Adole, R.H. Waghchaure, T.B. Pawar, B.S. Jagdale, K.H. Kapadnis, Synthesis, Molecular Structure, HOMO- LUMO and Spectroscopic Investigation of (E)-1-(2,4-Dichloro-5-fluorophenyl)-3- (2,6dichlorophenyl)prop-2-en-1-one: A DFT Based Computational Exploration, Asian J. Org. Med. Chem. 5(3) (2020) 242-248.

[22] V.A. Adole, T.B. Pawar, P.B. Koli, B.S. Jagdale, Exploration of catalytic performance of nano- $\mathrm{La}_{2} \mathrm{O}_{3}$ as an efficient catalyst for dihydropyrimidinone/thione synthesis and gas sensing, J. Nanostructure Chem. 9(1) (2019) 61-76.

[23] V.A. Adole, R.A. More, B.S. Jagdale, T.B. Pawar, S.S Chobe, Efficient synthesis, antibacterial, antifungal, antioxidant and cytotoxicity study of 2-(2hydrazineyl) thiazole derivatives, Chemistry Select 5(9) (2020) 2778-2786.

[24] M.A. El-Borai, H.F. Rizk, M.R. Sadek, M.M. El-Keiy, An eco-friendly synthesis of heterocyclic moieties condensed with pyrazole system under green conditions and their biological activity, Green Sustain. Chem. 6(2) (2016) 88-100.

[25] S.S. Chobe, V.A. Adole, K.P. Deshmukh, T.B. Pawar, B.S. Jagdale, Poly (ethylene glycol)(PEG-400): A green approach towards synthesis of novel pyrazolo [3,4d] pyrimidin-6-amines derivatives and their antimicrobial screening, Arch Appl. Sci. Res. 6(2) (2014) 61-66.

[26] K. Arulaabaranam, S. Muthu, G. Mani, S. Sevvanthi, Quantum mechanical computation, spectroscopic exploration and molecular docking analysis of 2Bromo-4-fluoroacetanilide, J. Mol. Struct. 1220 (2020) 128639.

[27] V.A. Adole, B.S. Jagdale, T.B. Pawar, A.A. Sagane, Ultrasound promoted stereoselective synthesis of 2,3-dihydrobenzofuran appended chalcones at ambient temperature, S. Afr. J. Chem. 73 (2020) 35-43.

[28] V.A. Adole, R.H. Waghchaure, B.S. Jagdale, T.B. Pawar, Investigation of Structural and Spectroscopic Parameters of Ethyl 4-(4-isopropylphenyl)-6methyl-2-oxo-1, 2, 3, 4-tetrahydropyrimidine-5-carboxylate: a DFT Study, Chem. Biol. Interf. 10(1) (2020) 22-30.

[29] J.P. Cornard, J.C. Merlin, Molecular structure and spectroscopic properties of 4 nitrocatechol at different $\mathrm{Ph}$ : UV-visible, Raman, DFT and TD-DFT calculations, Chem. Phys. 309(2-3) (2005) 239-249.

[30] V.A. Adole, R.H. Waghchaure, B.S. Jagdale, T.B. Pawar, S.S. Pathade, Molecular structure, frontier molecular orbital and spectroscopic examination on dihydropyrimidinones: a comparative computational approach, J. Adv. Sci. Res. 11(2) (2020) 64-70.

[31] J. Karpagam, N. Sundaraganesan, S. Sebastian, S. Manoharan, M. Kurt, Molecular structure, vibrational spectroscopic, first-order hyperpolarizability and HOMO, LUMO studies of 3-hydroxy-2-naphthoic acid hydrazide. J. Raman Spectrosc. 41(1) (2010) 53-62.

[32] V.A. Adole, B.S. Jagdale, T.B. Pawar, B.S. Desale, Molecular structure, frontier molecular orbitals, MESP and UV-visible spectroscopy studies of Ethyl 4- 3 , 4dimethoxyphenyl)-6-methyl-2-oxo-1,2,3,4-tetrahydropyrimidine-5carboxylate: A theoretical and experimental appraisal, Mat. Sci. Res. India. 17 (2020) 13-36.

[33] V.A. Adole T. B. Pawar, B.S. Jagdale, DFT computational insights into structural, electronic and spectroscopic parameters of 2-(2-Hydrazineyl) thiazole derivatives: a concise theoretical and experimental approach, J. Sulphur Chem. 42(2) (2020) 131-148.

[34] S.S. Pathade, V.A. Adole, B.S. Jagdale, T.B. Pawar, Molecular structure, electronic, chemical and spectroscopic (UV-visible and IR) studies of 5-(4chlorophenyl)-3-(3, 4-dimethoxyphenyl)-1-phenyl-4,5-dihydro-1H-pyrazole: combined DFT and experimental exploration, Mat. Sci. Res. India 17 (2020) $27-$ 40.

[35] V.A. Adole, B.S. Jagdale, T.B. Pawar, A.B. Sawant, Experimental and theoretical exploration on single crystal, structural, and quantum chemical parameters of 
(E)-7-(arylidene)-1,2,6,7-tetrahydro-8H-indeno [5,4-b] furan-8-one derivatives: A comparative study, J. Chin. Chem. Soc. 67(10) (2020) 1763-1777.

[36] V.A. Adole, V.R. Bagul, S.A. Ahire, R.K. Pawar, G.B. Yelmame, A.R. Bukane, Computational chemistry: molecular structure, spectroscopic (UV-visible and IR), electronic, chemical and thermochemical analysis of 3'-phenyl-1,2dihydrospiro[indeno[5,4-b], J. Adv. Sci. Res. 12(1) Suppl. 1 (2021) 276-286.

[37] T.B. Pawar, B.S. Jagdale, A.B. Sawant, V.A. Adole, DFT Studies of 2-[(2substitutedphenyl) carbamoyl] benzoic acids, J. Chem. Biol. Phys. Sci. 7 (2017) $167-175$
[38] A.B. Sawant R.S. Nirwan, Synthesis, characterization and DFT studies of 6,8dichloro-2-(4-chlorophenyl)-4H-chromen-4-one, Indian J. Pure Appl. 50 (2012) 308-313.

[39] R.S. Nirwan, A.B. Sawant, Experimental and theoretical studies of 6,8-dichloro2-(4-methoxyphenyl)-4H-chromen-4-one, Rasāyan J. Chem. 4 (2011) 613-619.

[40] M.J. Frisch, G.W. Trucks, H.B. Schlegel, G.E. Scuseria, M.A. Robb, Gaussian 03, Revision C.02, Gaussian, Inc., Wallingford CT, 2004. 